Case Report

\title{
A Congenital Anterior Urethrocutaneous Fistula in a Boy Whose Mother Was Exposed to Ionizing Radiations: Case Report and Literature Review
}

\author{
C. Spinelli, ${ }^{1}$ V. Pucci, ${ }^{1}$ C. Menchini, ${ }^{1}$ I. Buti, ${ }^{1}$ L. Fregoli, ${ }^{1}$ R. Spisni, ${ }^{1}$ and A. Mogorovich ${ }^{2}$ \\ ${ }^{1}$ Division of Pediatric Surgery, Department of Surgical, Medical, Molecular Pathology and of the Critical Area, 56124 Pisa, Italy \\ ${ }^{2}$ Department of Urology, University of Pisa, Pisa, Italy
}

Correspondence should be addressed to C. Spinelli; C.spinelli@dc.med.unipi.it

Received 6 January 2013; Accepted 31 January 2013

Academic Editors: A. Goel and E. Tuzel

Copyright ( $\odot 2013$ C. Spinelli et al. This is an open access article distributed under the Creative Commons Attribution License, which permits unrestricted use, distribution, and reproduction in any medium, provided the original work is properly cited.

\begin{abstract}
Anterior congenital urethrocutaneous fistula is a rare anomaly that may present in an isolated fashion or in association with other anomalies of the genital urinary tract or anorectal malformations. A case of congenital anterior urethrocutaneous fistula nonassociated with other congenital anomalies in a 3-year-old male whose mother has been exposed to Chernobyl's nuclear fallout is described. The patient was successfully operated with no recurrence. We report a review of the literature about etiology and surgical strategy including the role of ionizing radiations. The congenital anterior urethrocutaneous fistula represents a rare malformation. The etiopathogenesis is unknown.
\end{abstract}

\section{Introduction}

Primary anterior urethrocutaneous fistula is a very rare malformation with only 28 cases reported in English-language literature from 1962 to 2012 [1-20]. This anomaly is frequently associated with anorectal malformation or other anomalies of the genital-urinary tract, such as hypospadias, chordee, or cryptorchidism. It has been demonstrated that ionizing radiation can be the cause of congenital urogenital malformation.

We report an additional case of isolated congenital anterior urethrocutaneous fistula discussing its etiology as well as reviewing the literature.

\section{Case Presentation}

A 3 year old, Italian-Ukrainian, not circumcised male came to our attention for the presence of a fistula located on his ventral side of the penis since birth. He had no history of trauma or surgical intervention and his family history did not included hereditary diseases for genital-urinary tract malformations, but the mother was exposed to the nuclear fallout that followed the explosion of the Chernobyl nuclear power plant when she was 1 year old. The systemic and local physical examination of the patient was, except from the fistula, normal; the preputial skin was intact, both testicles were in place and chordee was absent as well as other anomalies. On the ventral side of the midshaft of the penis, an opening measuring $5 \times 3 \mathrm{~mm}$ was present (Figure 1). It was $2 \mathrm{~cm}$ distal to penoscrotal junction and easily passed by a $8 \mathrm{~F}$ urethral catheter. The urine was passing mostly through the fistula but also from the external urethral meatus. Investigations such as urine analysis, abdominal ultrasound, and cystourethrography were normal; so, we decided to operate the boy. The fistula was closed by one-stage transverse preputial onlay island flap urethroplasty over the $8 \mathrm{~F}$ tube that was kept in place for 7 days (Figure 2). After a 12-month followup, the child is healthy without recurrence.

\section{Discussion}

Anterior urethrocutaneous fistula without anorectal malformation or other anomalies of the genital-urinary tract, such as hypospadias, chordee, or cryptorchidism, is an extremely rare anomaly with just 28 cases previously reported in the literature (Table 1) [1-20]. 


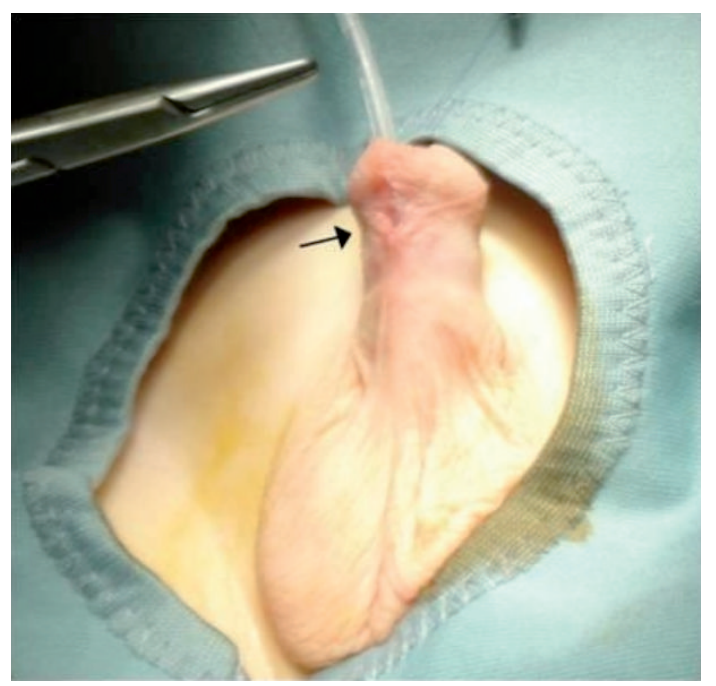

FIGURE 1: Congenital anterior urethrocutaneous fistula before surgery.

The etiology of congenital urethrocutaneous fistula is not clear yet as well as the exact development of the male urethra. In male fetuses, sexual differentiation and urethral development approximately begin at the 8 th week of development when, under the stimulation of testosterone, the urethral folds begin to close along the midline of ventral surface of the penis. Throughout a similar process, the proximal portion of the granular urethra form shortly thereafter and it is, thus, derived from the urethral plate, endodermal origin. According to the classical theory, the distal portion of the granular urethra is formed by lamellar ingrowth of the surface epithelium, ectodermal origin, which grows toward the distal extent of urethral plate, becoming stratified squamous epithelium around the 15th week. However, this theory for the development of the distal granular urethra has been challenged by the "endodermal differentiation theory." It has been suggested that the entire penile urethra might differentiate from the fusion of epithelial-mesenchymal interactions [21].

The variability of the patients reported leads to several pathogenetic theories of the congenital urethrocutaneous fistulas development. Campbell [23] proposed that congenital urethrocutaneous fistulas represent embryonal urethral blowouts behind a distal congenital obstruction. Olbourne [2] suggested that focal defect in the urethral plate results in arrested distal migration of the urethral plate or a localized deficiency of a portion of the plate, which prevents fusion of the urethral folds. Goldstein [24] theorized that there is a transient deficiency or inhibition of the local effect of testosterone leading to the failed closure of the urethral groove. Cook and Stephens [25] suggested an alternative mechanism that should be considered, namely, pressure atrophy from the heel of the baby's foot, leading to pressure necrosis. Karnak et al. [5] regarded congenital urethrocutaneous fistulas (excluding those associated with anorectal malformations) as one set of anomalies. Finally, in circumcised patient,

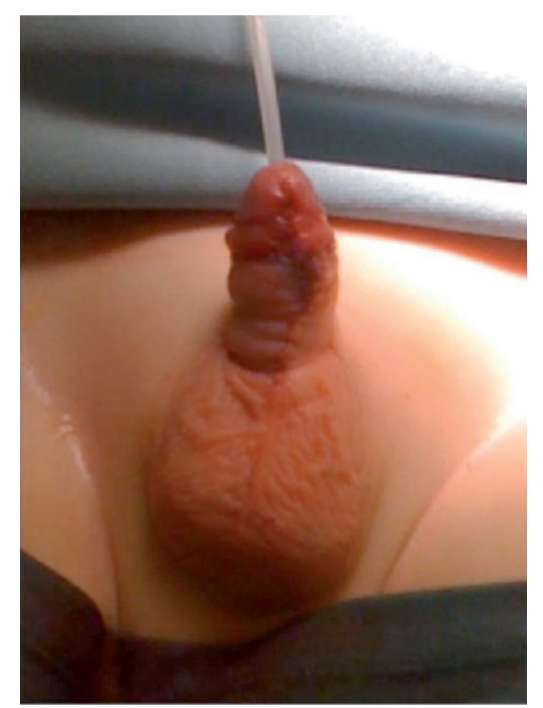

FIgURE 2: The ventral surface of the penis after immediately surgical correction by one-stage transverse preputial onlay island flap urethroplasty.

possible urethral injuries can be the cause of an acquired urethrocutaneous fistula [25].

Due to the frequent association of congenital urethrocutaneous fistulas with hypospadias and other genitourinary tract anomalies, some genetic pathogenetic theories have been proposed. Genetics studies proved that mutations of ATF 3 (activating transcription factor 3), an estrogens responsive gene expressed during genital development, $\mathrm{SHH}$ (sonic Hedge Hog), FGFs 8 and 10 (Fibroblast Growth Factors), Ephrin-B2 and receptors EphB2, Ephb3, often associated with genitourinary anomalies, are also implied in the genesis of isolate urethrocutaneous fistulas [26-29]. Moreover, it has been reported that environmental hazards like ionizing radiation can cause genitourinary tract anomalies, reinforcing the hypothesis concerning the cause-effect relationship between the presence of the congenital anterior urethrocutaneous fistula in our patient and the mother's exposure to ionizing radiation $[30,31]$.

According to the literature, several surgical techniques for the repair of isolated anterior urethrocutaneous fistula exist including pedicle flap, preputial bound skin flap, modified Denis Browne urethroplasty, or direct closure. The method of repair must be decided on the bases of the location and the size of the fistula and on the presence of other anomalies such as hypospadias or chordee [25]. One of the most important aspects to evaluate is the urethra beyond the fistula. If it is congenitally defective, the simple closure is usually unsuccessful and the fistula is likely to recur. If adequate lateral skin is present, repair can be carried out as one wound, performing a second-stage Johanson's urethroplasty [10]. Otherwise, an onlay flap can be also used. In our case, the fistula was an isolated abnormality and the urethra beyond the fistula was intact; so, a primary closure could have been possible if the dimension of the defect was inferior. This is the reason why we preferred the transverse preputial island flap 
TABLE 1: Literature review.

\begin{tabular}{|c|c|c|c|c|}
\hline Year & Author & Treatment & Case no. & Recurrence no. \\
\hline 1962 & Gupta [1] & Denis Browne & 1 & - \\
\hline 1976 & Olbourne [2] & Denis Browne & 2 & 2 \\
\hline 1994 & Ritchey et al. [3] & Three-layer closure & 1 & - \\
\hline 1994 & Tannenbaum and Palmer [4] & Thiersch-Duplay & 2 & - \\
\hline 1995 & Karnak et al. [5] & Proximal-based skin flap & 1 & 1 \\
\hline 1997 & Barwell and Harris [6] & Preputial flap & 1 & - \\
\hline 1997 & Maarafie and Azmy [7] & Preputial flap & 1 & - \\
\hline 1999 & Caldamone et al. [8] & Thiersch-Duplay & 6 & - \\
\hline 2000 & Nakane et al. [11] & Preputial flap & 1 & - \\
\hline 2000 & Sharma et al. [9] & Two-layer closure & 1 & - \\
\hline 2000 & Harjai [10] & Preputial flap & 1 & - \\
\hline 2003 & Betalli et al. [12] & Three-layer closure & 1 & 1 \\
\hline 2004 & Agarwal [13] & Local skin turndown flap & 1 & - \\
\hline 2005 & Akman et al. [14] & Preputial flap & 1 & - \\
\hline 2006 & Ceylan et al. [15] & Preputial flap & 1 & - \\
\hline 2008 & Rashid et al. [16] & Thiersch-Duplay & 1 & - \\
\hline 2008 & Arena et al. [17] & Three-layer closure & 1 & - \\
\hline 2013 & Spinelli et al. [22] & Preputial flap & 1 & - \\
\hline 2009 & Galinier et al. [18] & Bladder mucosal graft & 1 & - \\
\hline 2011 & Jindal et al. [19] & Two-layer closure & 1 & - \\
\hline 2011 & Chen et al. [20] & Local skin turndown flap & 1 & - \\
\hline Total & & & 28 & 4 \\
\hline
\end{tabular}

to repair the lesion; another reason was also because the flap seems to maintain a stable, well-vascularised thick adequately durable tissue to cover the lesion.

The congenital anterior urethrocutaneous fistula represents, as our work and the literature review demonstrate, a rare malformation. The etiopathogenesis is unknown and the case we described is particularly interesting because the mother was exposed, during the pediatric age, to the nuclear fallout that followed the explosion of the Chernobyl nuclear power plant; this opens an interesting and extensive discussion on the possible correlation between the isolated urethrocutaneous fistula and the exposure to ionizing radiations.

\section{Consent}

A written informed consent was obtained from the patient's legal guardian for publication of this paper and accompanying images. A copy of the written consent is available for review by the Editor-in-Chief of this journal.

\section{References}

[1] S. C. Gupta, "An unusual type of hypospadias," The British Journal of Plastic Surgery, vol. 15, pp. 191-193, 1962.

[2] N. A. Olbourne, "Congenital urethral fistula: case reports," Plastic and Reconstructive Surgery, vol. 57, no. 2, pp. 237-239, 1976.
[3] M. L. Ritchey, A. Sinha, and L. Argueso, "Congenital fistula of the penile urethra," Journal of Urology, vol. 151, no. 4, pp. 10611062, 1994.

[4] S. Y. Tannenbaum and L. S. Palmer, "Congenital urethrocutaneous fistula," Journal of Urology, vol. 43, no. 1, pp. 98-99, 1994.

[5] I. Karnak, F. C. Tanyel, and A. Hiçsonmez, "Congenital urethrocutaneous fistula: a case report and literature review, with a nomenclature proposal," Journal of Pediatric Surgery, vol. 30, no. 10, pp. 1504-1505, 1995.

[6] J. Barwell and D. Harris, "Case report: congenital urethrocutaneous fistula," Journal of Anatomy, vol. 190, no. 1, pp. 155-156, 1997.

[7] A. Maarafie and A. F. Azmy, "Congenital fistula of the penile urethra," The British Journal of Urology, vol. 79, no. 5, article 814, 1997.

[8] A. A. Caldamone, S. C. Chen, J. S. Elder, M. L. Ritchey, D. A. Diamond, and M. A. Koyle, "Congenital anterior urethrocutaneous fistula," Journal of Urology, vol. 162, no. 4, pp. 1430-1432, 1999.

[9] A. K. Sharma, S. K. Kothari, D. Goel, and V. Chaturvedi, "Congenital urethral fistula," Pediatric Surgery International, vol. 16, no. 1-2, pp. 142-143, 2000.

[10] M. M. Harjai, “Congenital urethrocutaneous fistula," Pediatric Surgery International, vol. 16, no. 5-6, pp. 386-387, 2000.

[11] A. Nakane, Y. Hayashi, Y. Kojima et al., "Congenital urethrocutaneous fistula," International Journal of Urology, vol. 7, no. 9, pp. 343-344, 2000.

[12] P. Betalli, E. Carretto, P. Midrio, G. F. Zanon, and P. G. Gamba, "A new indication for buccal mucosal graft: isolated congenital fistula of the penile urethra," Pediatric Surgery International, vol. 19, no. 8, pp. 586-587, 2003. 
[13] P. Agarwal, "Congenital anterior urethrocutaneous fistula revisited," Indian Journal of Plastic Surgery, vol. 37, pp. 64-66, 2004.

[14] R. Y. Akman, K. Cam, O. Akyuz, and A. Erol, "Isolated congenital urethrocutaneous fistula," International Journal of Urology, vol. 12, no. 4, pp. 417-418, 2005.

[15] K. Ceylan, B. Köseoğlu, O. Tan, and B. Atik, "Urethrocutaneous fistula: a case report," International Urology and Nephrology, vol. 38, no. 1, pp. 163-165, 2006.

[16] K. A. Rashid, S. N. Kureel, and R. K. Tandon, "Congenital anterior penile isolated fistula: a case report," African Journal of Paediatric Surgery, vol. 5, no. 1, pp. 52-53, 2008.

[17] F. Arena, G. Scalfari, P. Impellizzeri, P. Antonuccio, and C. Romeo, "Case report of congenital fistula of the penile urethra," Minerva Pediatrica, vol. 60, no. 2, pp. 255-257, 2008.

[18] P. Galinier, S. Mouttalib, L. Carfagna, P. Vaysse, and J. Moscovici, "Congenital anterior urethrocutaneous fistula associated with a stenosis of the bulbar urethra in the context of high anorectal malformation without fistula," Journal of Plastic, Reconstructive and Aesthetic Surgery, vol. 62, no. 2, pp. ell-e13, 2009.

[19] T. Jindal, M. R. Kamal, S. N. Mandal, and D. Karmakar, "Isolated congenital urethrocutaneous fistula of the anterior urethra," Korean Journal of Urology, vol. 52, no. 5, pp. 368-370, 2011.

[20] Q. Chen, W. L. Xiao, Y. M. Jiang, and L. J. Sun, "Adult isolated congenital anterior urethrocutaneous fisula," Urologia Internationalis, vol. 86, pp. 361-364, 2011.

[21] E. A. Kurzrock, L. S. Baskin, and G. R. Cunha, "Ontogeny of the male urethra: theory of endodermal differentiation," Differentiation, vol. 64, no. 2, pp. 115-122, 1999.

[22] C. Spinelli, V. Pucci, C. Menchini et al., "A congenital anterior urethrocutaneous fistula in a boy whose mother was exposed to ionizing radiations: case report and literature review," Case Reports in Urology. In press.

[23] M. Campbell, Clinical Pediatric Urology, WB Saunders, Philadelphia, Pa, USA, 1951.

[24] M. Goldstein, "Congenital urethral fistula with chordee," Journal of Urology, vol. 113, no. 1, pp. 138-140, 1975.

[25] W. A. Cook and F. S. Stephens, "Pathoembryology of the urinary tract," in Urological Surgery in Neonates and Young Infants, L. R. King, Ed., Saunders, Philadelphia, Pa, USA, 1988.

[26] C. Dravis, N. Yokoyama, M. J. Chumley et al., "Bidirectional signaling mediated by ephrin-B2 and EphB2 controls urorectal development," Developmental Biology, vol. 271, no. 2, pp. 272290, 2004.

[27] A. Beleza-Meireles, V. Tohoren, C. Soderhall et al., "Activating transcription factor 3: a hormone responsive gene in the etiology of hypospadias," European Journal of Endocrinology, vol. 158, pp. 729-739, 2008.

[28] M. H. Wang and L. S. Baskin, "Endocrine disruptors, genital development, and hypospadias," Journal of Andrology, vol. 29, no. 5, pp. 499-505, 2008.

[29] N. Kalfa, B. Liu, O. Klein, M. H. Wang, M. Cao, and L. S. Baskin, "Genomic variants of ATF3 in patients with hypospadias," Journal of Urology, vol. 180, no. 5, pp. 2183-2188, 2008.

[30] J. P. Bonde, "Male reproductive organs are at risk from environmental hazards," Asian Journal of Andrology, vol. 12, no. 2, pp. 152-156, 2010.

[31] X. Y. Qin, Y. Kojima, K. Mizuno et al., "Association of variants in genes involved in environmental chemical metabolism and risk of cryptorchidism and hypospadias," Journal of Human Genetics, vol. 57, no. 7, pp. 434-441, 2012. 


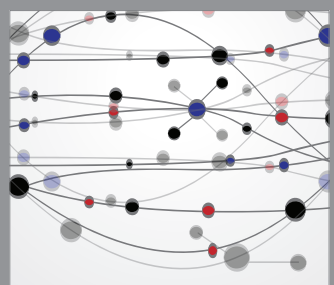

The Scientific World Journal
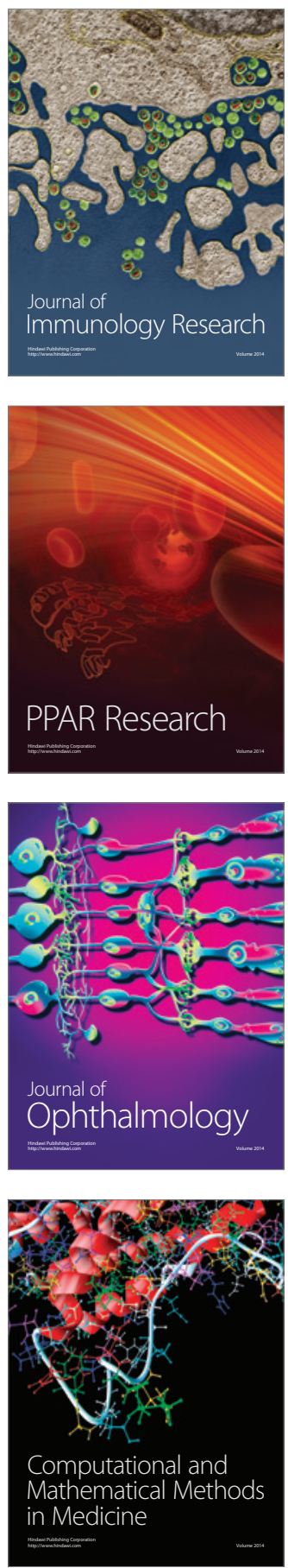

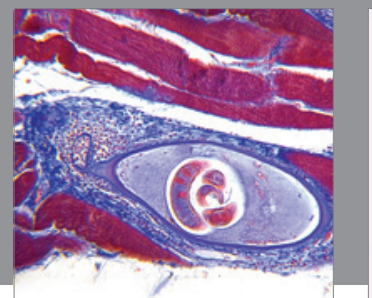

Gastroenterology

Research and Practice
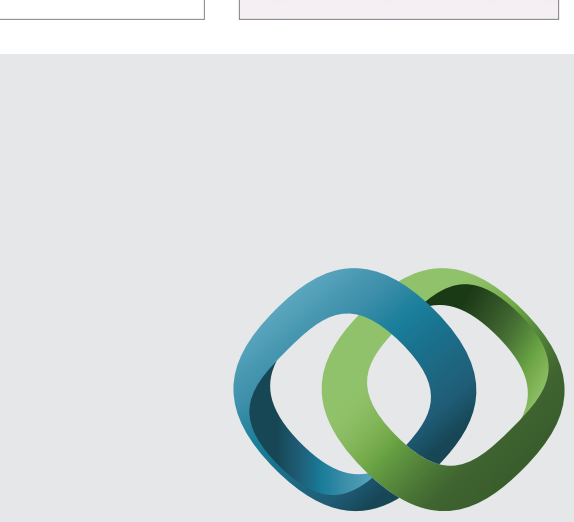

\section{Hindawi}

Submit your manuscripts at

http://www.hindawi.com
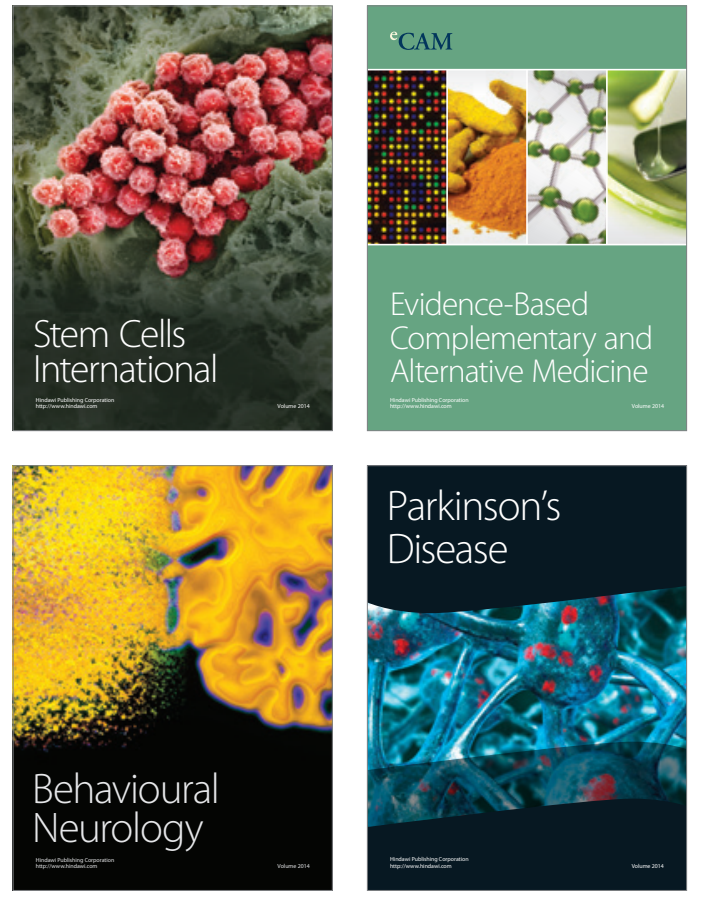
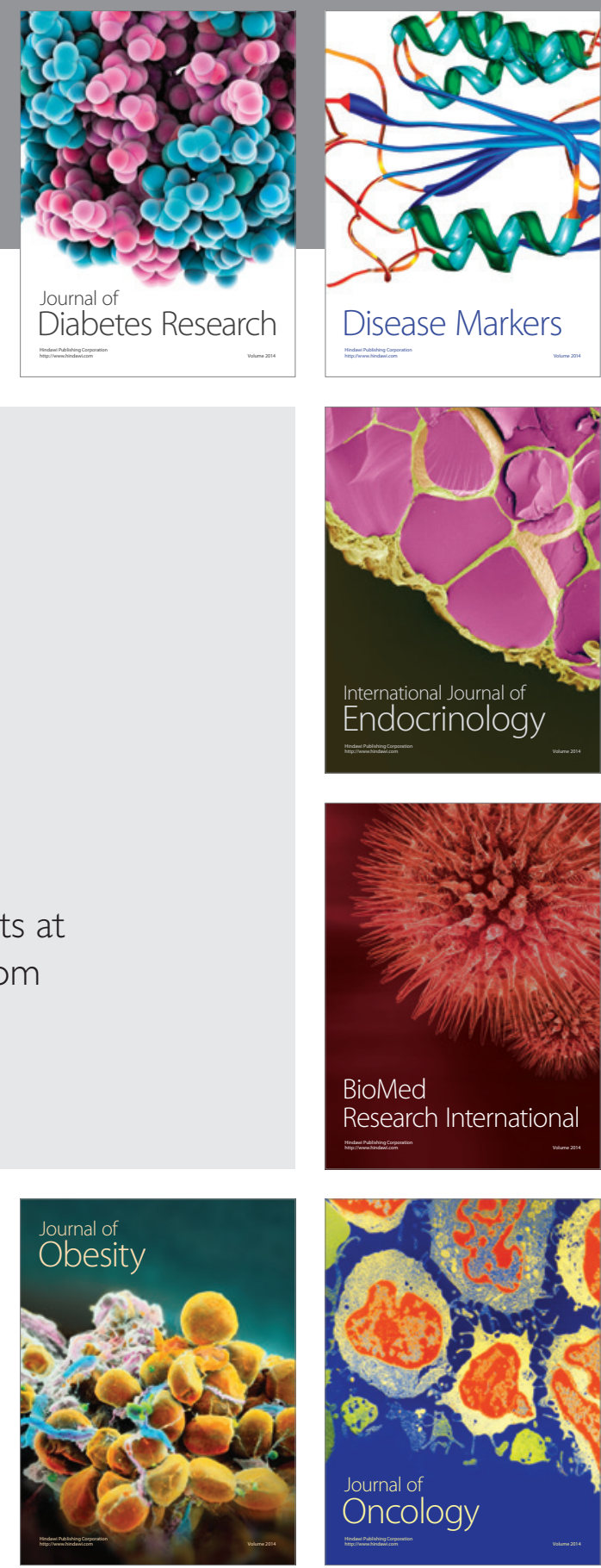

Disease Markers
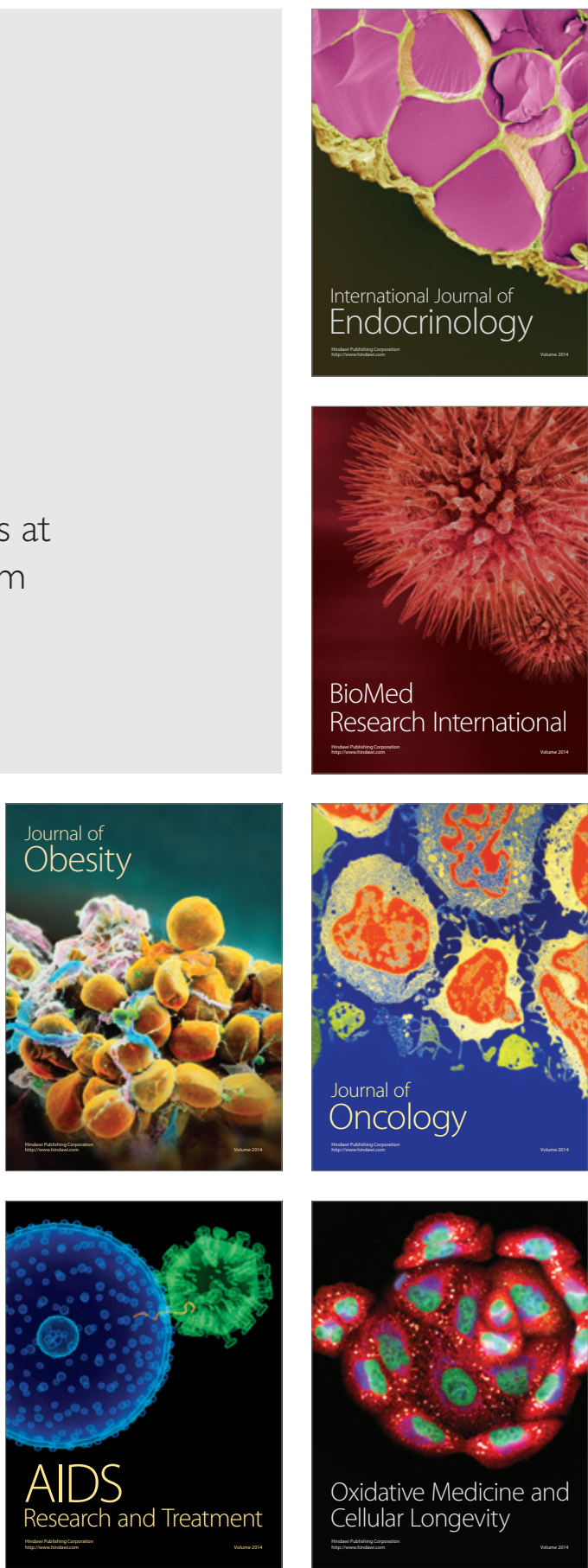